\title{
TOPOLOGY OPTIMISATION OF HYDRAULIC PRESS STRUCTURE
}

\author{
P.S Burli ${ }^{1}$

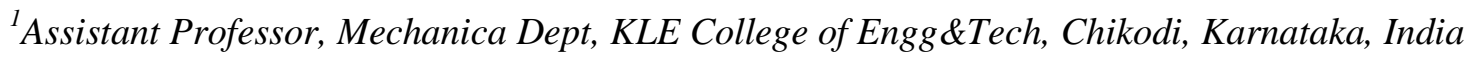

\begin{abstract}
Topology optimisation is carried out to find the zones of material removal on final size optimised structure. The results are represented and density plots are presented. The zones represented by blue can be removed for better material saving. The density plots are represented showing convergence of solution rapidly in the beginning and slowly in the later iterations. Finally wolf's law is applied for material removal and addition for better strength. After iterations, the results are presented for vonmises and displacements. The results shows a vonmises stress of around $105 \mathrm{~N} / \mathrm{mm} 2$ and a displacement value of $1.457 \mathrm{~mm}$. The final weight is observed to be around $15501 \mathrm{kgs}$. The results shows efficiency of combination of three techniques in reducing the weigh of machine structures efficiently and useful for industrial applications as a combination. All the results are represented with necessary graphical pictures. The geometry is removed based on topology optimization and results are obtained based on wolff's law. The structural results are presented.
\end{abstract}

Keywords: Topoloyg1, optimisation2, vonmises stress3, Hydraulic press 4 etc...

$* * *$

\section{INTRODUCTION}

A Hydraulic press is a machine in which a large force is exerted on the larger of two pistons in a pair of hydraulically coupled cylinders by means of a relatively small force applied to the smaller piston. Whereas, a Mechanical press is a machine that exerts pressure to form or shape or cut materials or extract liquids or compress solids Hydraulic presses are custom designed to individual specifications and features, with the highest quality materials to withstand hard use and to offer a wide range of engineering and operational advantages to the users along with the longer trouble free operation life.

\section{DEFINITION}

Optimization is quite an interesting aspect of engineering practice that cuts across all branches of engineering. In the production sector, for example, the reduction of material (Figure 1.1) used in manufacturing is possible when optimization is incorporated beforehand.

Integrated study of usage of design optimisation, Topology optimisation and Wolf's law in reducing the weight of structure within the functional requirements (displacement and stress) of the problem.

\section{PROBLEM REQUIREMENTS}

Present day design is for optimum things like cost, weight etc. Reduction of weight within the allowable stress and deflection range is very important to reduce the effect of dynamic loads on the structure.

\subsection{Main Objective}

Modelling of the problem for the given dimensions Representation of the problem using APDL Iterating the problem for the best design sets Application of topology optimisation for volume reduction Wolff's law in reducing the weigh Integrated study of the problem

\section{ELEMENTS USED}

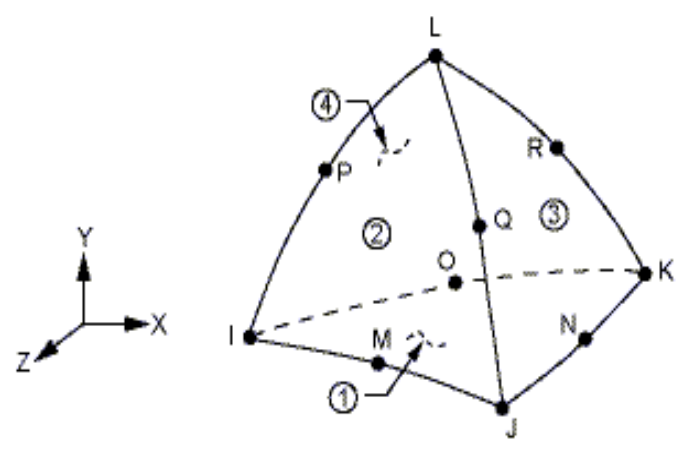

Fig -1:8 noded solid45

\section{DESIGN REQUIREMENTS}

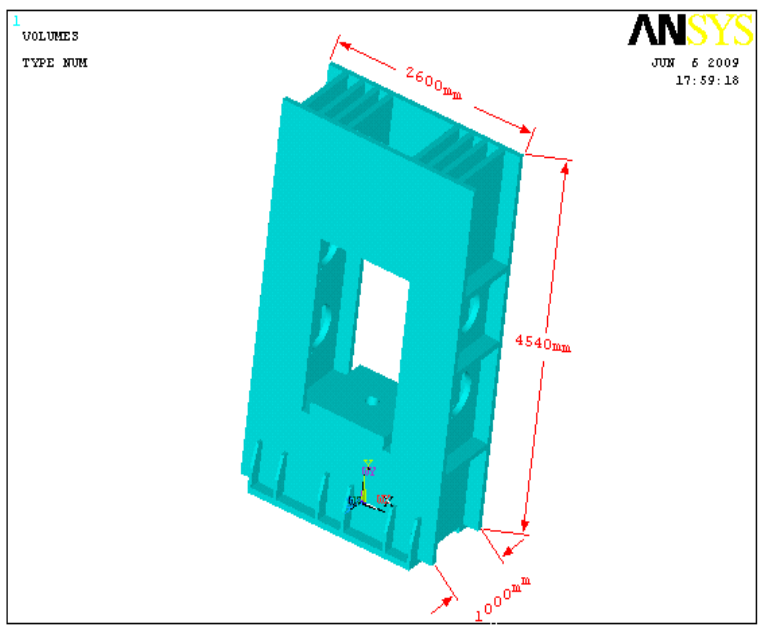

Fig -2: 800 tone press structure for forge welding 
Maximum deformation allowed $=3 \mathrm{~mm}$

Allowable stress $=180 \mathrm{~N} / \mathrm{mm}^{2}$

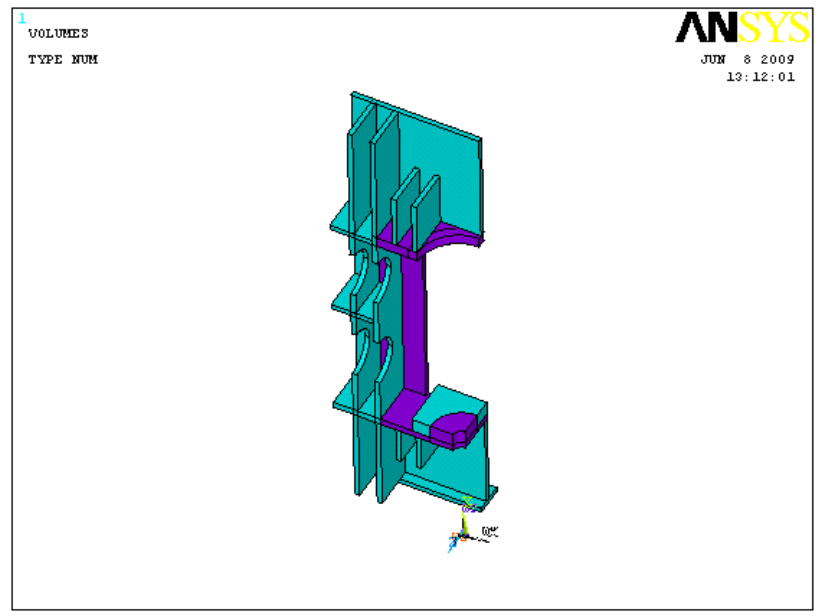

Fig -3: Topo Geometry

The above picture shows geometry to be optimised for topology optimisation. Topology optimisation is similar to shape optimisation. Two colours are shown in the picture. The inner colours represents the geometry which is necessary for load application and other geometry will be optimised for topology

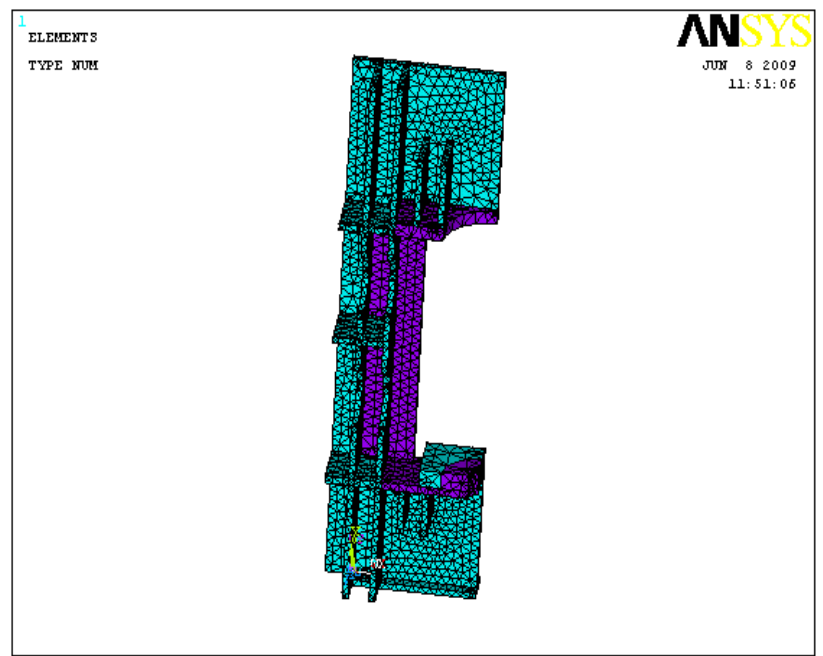

Fig -4: Topology geometry

The above picture represents meshed plot for topology optimisation. The above picture shows topology geometry with different colours. The blue colour geometry is meshed with solid92 for topology optimisation and the other colour shows the minimum required geometry which includes loading, constraint geometry.

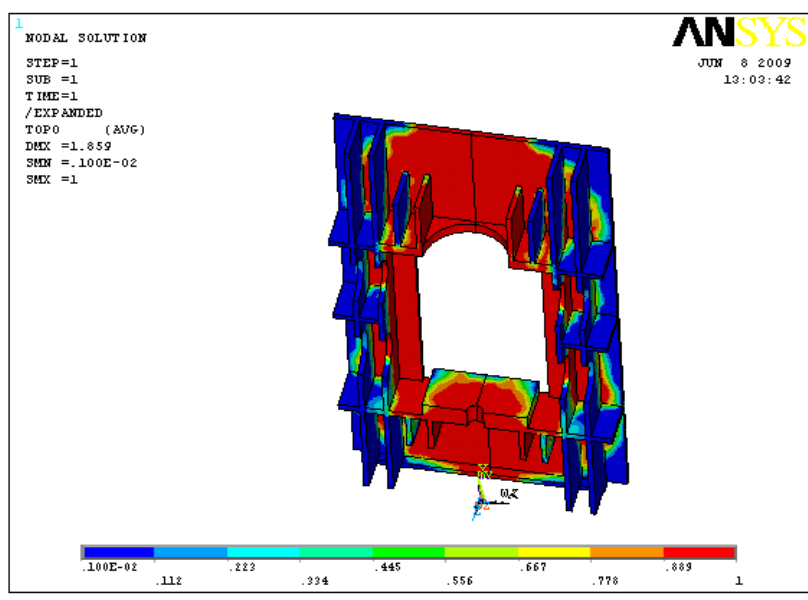

Fig -5: Density plot

The above picture represents stiffness plot from topology optimisation. The blue represents the material which can be removed.

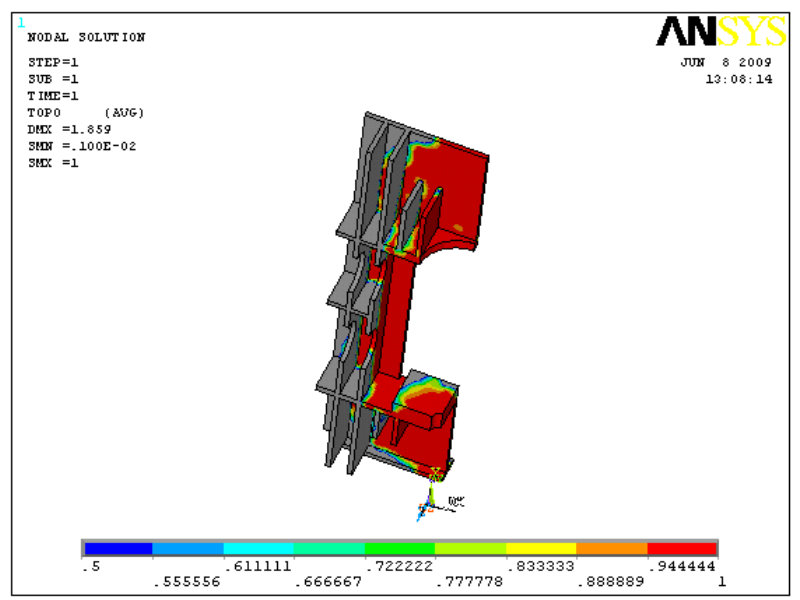

Fig -6: Density plot between 5 to 1 stiffness

The above picture represents stiffness plot between 0.5 to 1 . The material requirement is shown above.

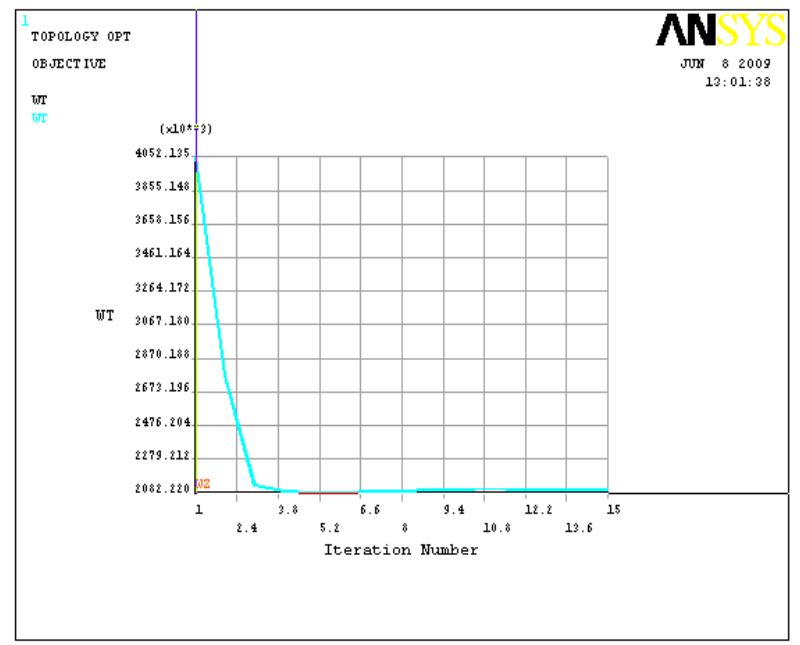

Fig -7: Weight vs Iteration number 
The above plot represents variation of objective function with reference to iteration numbers. More drop of weight can be observed in the beginning and later almost negligible drop as convergence is taking place.

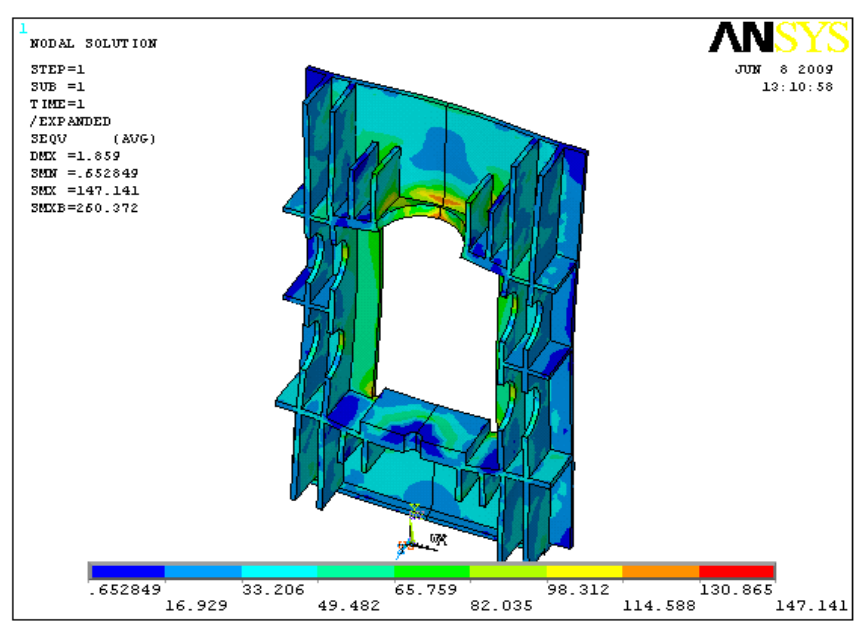

Fig -8: Vonmises Stress plot

The above picture represents vonmises stress in the structure. The maximum stress equal to $147.141 \mathrm{Mpa}$ which is less than the allowable stress of the material. So structure is safe from stress point of view.

\section{STATISTICS FROM TOPOLOGY}

\section{OPTIMISER}

\section{Objective Function:}

Reference name $=\mathrm{wt}$

Initial value $=0.405214 \mathrm{e}+07$

Current value $=0.210496 \mathrm{e}+07$

Constraint function(s):

Reference name $=$ volume

Number of elements considered for optimization $=12638$

Dimensionality $=3 \mathrm{~d}$

Total number of iterations performed $=15$

Accuracy used for termination check $=0.100000 \mathrm{e}-03$

Convergence status = converged

Active solution approach $\quad=\mathrm{oc}$

The above values represented converged history of the problem. The problem is converged with in the tolerance of .0001 . With in 15 iterations, problem is converged. The volume reduction can be observed to be almost $48 \%$. The volume history is shown below.

Table -1: Volume history of the problem

\begin{tabular}{|l|l|}
\hline Iteration Number & Volume $\left(\mathrm{mm}^{3}\right)$ \\
\hline 1 & $0.40521 \mathrm{E}+07$ \\
\hline 2 & $0.27675 \mathrm{E}+07$ \\
\hline 3 & $0.21260 \mathrm{E}+07$ \\
\hline 4 & $0.20915 \mathrm{E}+07$ \\
\hline 5 & $0.20822 \mathrm{E}+07$ \\
\hline 6 & $0.20831 \mathrm{E}+07$ \\
\hline 7 & $0.20894 \mathrm{E}+07$ \\
\hline 8 & $0.20957 \mathrm{E}+07$ \\
\hline
\end{tabular}

\begin{tabular}{|l|l|}
\hline 9 & $0.21008 \mathrm{E}+07$ \\
\hline 10 & $0.21030 \mathrm{E}+07$ \\
\hline 11 & $0.21063 \mathrm{E}+07$ \\
\hline 12 & $0.21058 \mathrm{E}+07$ \\
\hline 13 & $0.21053 \mathrm{E}+07$ \\
\hline 14 & $0.21049 \mathrm{E}+07$ \\
\hline 15 & $0.21050 \mathrm{E}+07$ \\
\hline
\end{tabular}

The above volume values are not the real values, as each element is assigned with dummy volume, density for stiffness calculations to get uniform strength. It represents iteration values from the initial value to the final value. This optimization history is to plot the various compliance in the system.

\section{APPLICATON OF WOLFF'S LAW}

Wolff's law is further applied to reduce the material requirement and for uniform stress generation. So structure is further designed based on wolf's law. The results are summarised as follows.
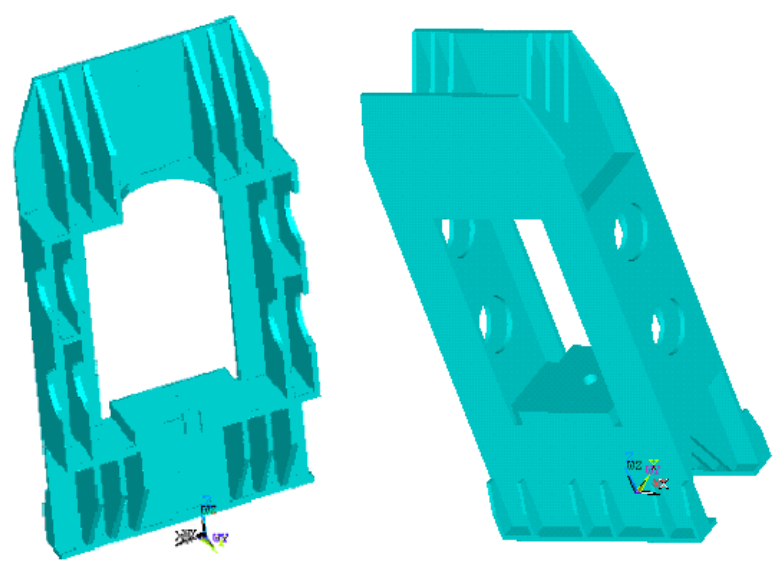

Fig -9: Geometry of the optimized model

The above picture shows edge geometry of the problem. . The material removal is based on the topology optimization for uniform strength of the structure.

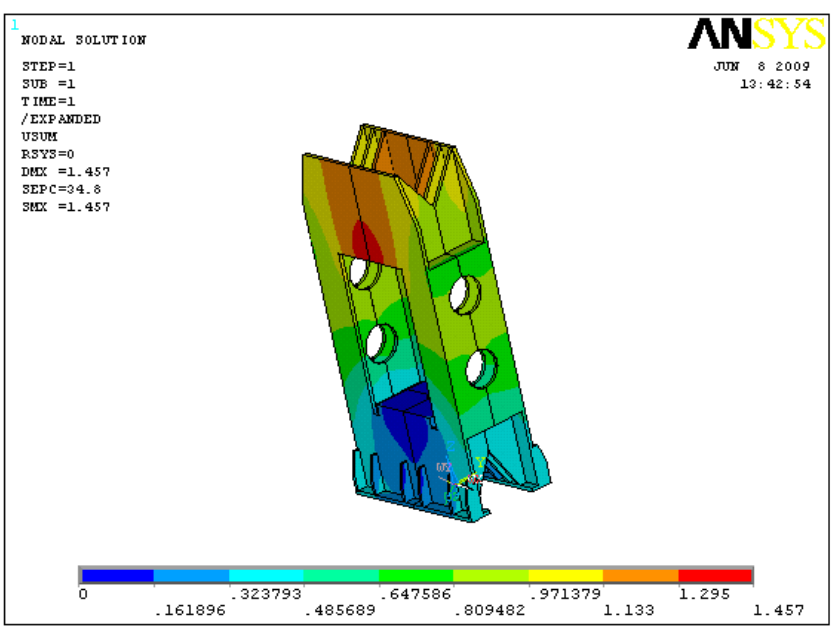

Fig -10: Displacement plot on the structure 
The above picture represents displacement plot of the problem. Maximum displacement is around 1.457 from the final optimization using Wolff' law. The color red shows maximum displacement position. This displacement is much smaller than the allowable deflection of the problem.

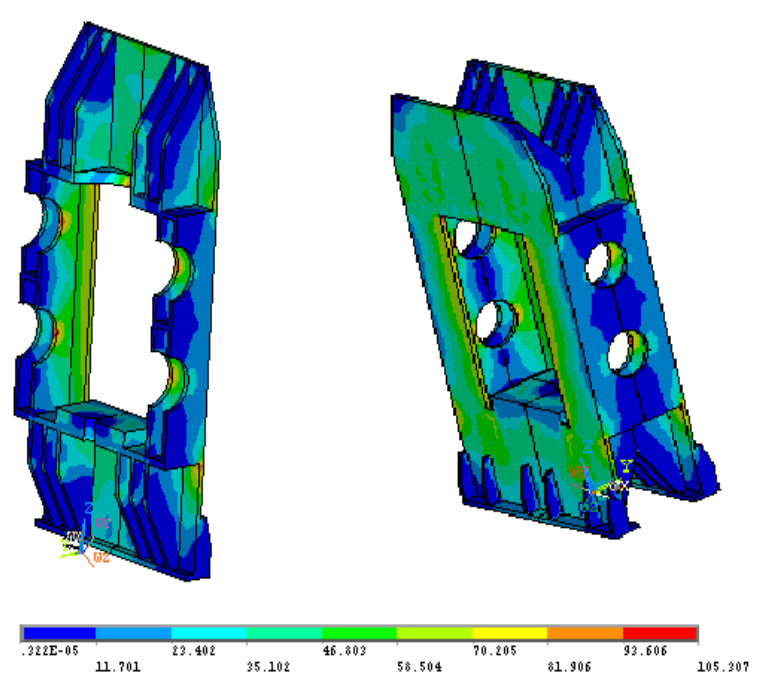

Fig -11: Vonmises stress after application of wolf's law

The above picture shows vonmises stress obtained in the problem. The geometry is optimized for stress and weight keeping functional requirements under satisfaction. Maximum stress observed to be around $105.387 \mathrm{~N} / \mathrm{mm} 2$ which is well under the safety for the material. From the calculation from ansys volume of the geometry is around $0.19874 \mathrm{E}+10$ which shows a weight of around $15501 \mathrm{kgs}$.

\section{DISCUSSION}

After observation of the final size optimisation, still much scope can be observed on the sketches for material optimization. So topology optimization is carried out to observe the stress zones. The topology optimization results are presented for density variation. The results shows higher drop of weight in the beginning and almost flat variation in the lateral iterations showing the convergence of the problem. By observing the topology stress distribution, wolff's law is applied to reduce the material and some material is added to improve the stiffness of the member. After iterations, the final solution results are presented which shows a maximums vonmises stress of $105 \mathrm{~N} / \mathrm{mm}^{2}$ and $1.457 \mathrm{~mm}$ deflection. The total weight $\mathrm{I}$ is observed to be $15501 \mathrm{kgs}$. So by these three optimization techniques, more drop can be observed in the total weight of the structure

\section{CONCLUSION}

The hydraulic pressing structure used for forging operation is optimized using three techniques namely design optimization, Topology optimization and Wolf's law. The conclusions are as follows
The hydraulic pressing machine for 800 tones load is modeled using Ansys parametric design language using scalar parameters.

Due to symmetry only quarter section is built The boundary conditions are applied and problem is solved in static domain. The results shows maximum vonmises stress of around $71.851 \mathrm{~N} / \mathrm{mm} 2$ and displacement of around $0.7077 \mathrm{~mm}$. The structure is optimised for weight using design optimiser which is based on size optimisation. The design and state variables are set and weight is set as objective function.

A total of 13 feasible sets are obtained and best set weight is observed to be around $4625.7 \mathrm{~kg}$ for quarter section and $18502 \mathrm{kgs}$ for full structure. The optimised structure vonmises stress is around $136 \mathrm{~N} / \mathrm{mm} 2$ and deflection of around $1.67 \mathrm{~mm}$. Graphs are represented for variation of geometry (Weight), vonmises and deflection with reference to number of iterations. The graphs shows drop of weight with reference to increased number of iterations. Also stress and deflection can be observed in the structure. But finally around $23 \%$ weight reduction can be observed at the end of size optimisation.Further topology optimization is carried out to find the zones of material removal. The results are represented and density plots are presented. The zones represented by blue can be removed for better material saving. The density plots are represented showing convergence of solution rapidly in the beginning and slowly in the later iterations. Finally wolf's law is applied for material removal and addition for better strength. After iterations, the results are presented for vonmises and displacements. The result shows a vonmises stress of around $105 \mathrm{~N} / \mathrm{mm} 2$ and a displacement value of $1.457 \mathrm{~mm}$. The final weight is observed to be around $15501 \mathrm{kgs}$. The results shows efficiency of combination of three techniques in reducing the weigh of machine structures efficiently and useful for industrial applications as a combination. All the results are represented with necessary graphical pictures. The geometry is removed based on topology optimization and results are obtained based on wolff's law. The structural results are presented

\section{REFERENCES}

[1]. R.J.Duffin, E.L.Peterson and C.Zener, Geometric programming: theory and applications, Wiley, New york, 1967.

[2]. G.B.Dantzig Linear Programming and Extensions, Princeton University Press.

[3]. R. A. Gettatly and R. H. Gallagher, "A procedure for automated minimum weight structural design, Part

[4]. I - Theoretical basis, Part II - Applications," Aero. Quart. Part I, Vol. 17, pp. 216-230 and pp.332-342, 1966.

[5]. M.M. Denn, Optimisation by variational methods, McGraw-Hill, New York 1969.

[6]. G.S.G. Beveridge and R.S. Schechter, Optimisation : theory and practice, McGraw-Hill, New York, 1970.

[7]. J.L. Kuester and J.H. Mize, Optimisation techniques with FORTRAN, McGraw-Hill, New York, 1973. 
[8]. M.J. Panik, Classical Optimisation: foundations and extensions, North-Holland Publishing Co., Amsterdam, 1976.

[9]. D. Koo, “Elements of Optimisation” Springer-Verlag, New York, 1977.

[10]. D.G. Carmichael, Structural modeling and Optimisation, Ellis Horwood Chichester, 1981.

[11]. Morris,A.J. Foundations of structural optimization: a unified approach. John Wiley \& Sons, 1st ed., UK, 1982

[12]. Y. M. Xie and G. P. Steven, "A simple evolutionary procedure for structural Optimisation," Comp.Struct. Vol. 49, pp. 885-896, 1993.

[13]. S.S. Rao - Optimization, Theory and Applications, Wiley inter-science, 1996

[14]. Ernst Hustedt, AMES Ltd. 1999, (Air New Zealand Engineering).

[15]. Jim Patterson (Hendrickson Trailer Suspension Systems). 2000.

[16]. Finite Element Procedures - Klaus-Jurgen Bathe, Prentice Hall of India Pvt. Ltd.- Sixth Edition 2002.

[17]. Introduction to the Finite Element Method, Desai/Abel - CBS publishers 2002.

[18]. Finite Element Analysis - C.S. Krishnamoorthy, Second Edn, TMH - 2002.

[19]. Hursha Narayan (Robert Bosch Corporation). 2002

[20]. Joe Metrisin (Florida Turbine Technologies, Inc.). 2002

[21] Concepts and Application of Finite Element Analysis Rober D. Cook, David S - Joh Wiely \& Sons Pte. Ltd. Fourth Edition 2003.

[22]. Finite Elements in Engineering - Tirupathi R. Chandrupatla, Ashok D. Belegundu, Prentice - Hall of India Pvt. Ltd, 2003

\section{BIOGRAPHIES}

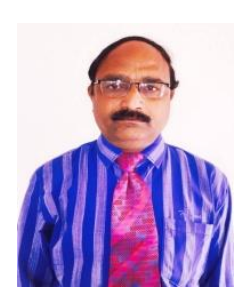

Working as Asst.Professor in Mechanical Dept, in KLE college of Engineering\& Technology, Chikodi, Dist-Belgaum, Karnataka state. Total Teaching experience is 15 years. Attended many workshops, published Three papers in international Journals and presented papers in conference 